\title{
Substituent distribution in highly branched dextrins from methylated starches
}

\author{
Yuri E.M. van der Burgt ${ }^{\text {a }}$, Jack Bergsma ${ }^{\text {b }}$, Ido P. Bleeker ${ }^{b}$, Paul J.H.C. Mijland ${ }^{b}$, \\ Johannis P. Kamerling ${ }^{\mathrm{a}, *}$, Johannes F.G. Vliegenthart ${ }^{\mathrm{a}}$ \\ ${ }^{a}$ Department of Bio-Organic Chemistry, Bijvoet Center, Utrecht University, PO Box 80.075, \\ NL-3508 TB Utrecht, The Netherlands \\ ${ }^{\mathrm{b}}$ AVEBE Research and Development, AVEBE-weg 1, NL-9607 PT Foxhol, The Netherlands
}

Received 2 November 1999; accepted 10 February 2000

\begin{abstract}
Granular potato starch and amylopectin potato starch were methylated to molar substitutions (MS) up to 0.29. Extensive alpha-amylase digestion gave mixtures of partially methylated oligomers. Precipitation of larger fragments by methanol yielded mainly $\alpha$-limit dextrins (84-99\%). Methanol precipitates were extensively digested with betaamylase yielding $\alpha, \beta$-limit dextrins. The average substitution level of branched glucose residues in the dextrins thus obtained was determined after per deuteriomethylation by using FAB mass spectrometry, and compared with that of the linearly linked glucose residues. The present work demonstrates that methylation does not show any preference for substitution at either branched or linearly linked glucose residues, taking into account the inherently lower amount of substitution sites at branched residues. The results corroborate earlier studies wherein it was found that substituents in branched regions are distributed almost randomly. In addition, the data enable the determination of the average degree of branching of partially methylated dextrins. (C) 2000 Elsevier Science Ltd. All rights reserved.
\end{abstract}

Keywords: Methylated starches; Amylopectin potato starch; Branching; Amylolysis; Substituent distribution

\section{Introduction}

Starch, the main energy reserve of higher plants, consists of amylose and amylopectin. Amylose is considered as an essentially $(1 \rightarrow$ 4)-linked $\alpha$-D-glucan, whereas amylopectin contains up to $5 \%$ of branched $\alpha$-D-glucose residues. The short amylopectin side chains are $(1 \rightarrow 6)$-linked to longer chains [1] and arranged in double helices, building up the organised crystalline framework of the starch granule [2,3]. Molecular mass distribution,

* Corresponding author. Tel.: + 31-30-2533479/2184; fax: $+31-30-2540980$.

E-mail address: kame@boc.chem.uu.nl (J.P. Kamerling). amylose and amylopectin content, and the degree of branching of these molecules depend on the botanical source of the starch granules $[1,4,5]$.

Chemical modifications of starches provide starch products that fulfil various demands [6]. Detailed information on the distribution of substituents can contribute to the understanding of relations between molecular structure and functional properties, thus opening ways to more-rational derivatisation processes. Previously, we reported that in methylated starches, crystalline linear amylopectin side chains, which play an important role in the retrogradation of gelatinised starches, contain fewer substituents than amorphous branched parts $[7,8]$. The aim of the present study is to 
examine the substitution pattern in branched regions of methylated starches in more detail to determine whether preferences exist for substitution sites at branched glucose residues.

\section{Results and discussion}

Preparation of methylated starches.Methylated potato starches (P) and methylated amylopectin potato starches (A) were prepared by methylation of starch granules in an alkaline aqueous suspension using dimethyl sulfate [8]. The molar substitution (MS) values of the starch derivatives studied are listed in Table 1. The MS values and the monosaccharide compositions of the intact granules of P10, P20, P30, A10, A20 and A30 were determined by using GLC and have been reported previously [7].

Preparation of $\alpha, \beta$-dextrins from methylated starches.-Gelatinised methylated starches P10-P30 and A10-A30 were extensively digested with alpha-amylase from Bacillus subtilis [9], yielding mixtures of $(1 \rightarrow 4)-\alpha-\mathrm{D}-$ glucans of different sizes with varying degrees of $(1 \rightarrow 6)$ branching (DB). The so-called $\alpha$ limit dextrins, which are highly branched and have a degree of polymerisation (DP) $>8$ (as determined by high-performance liquid chromatography (HPLC) [7]), were separated from the linear oligomers by precipitation with methanol. The MS values of the $\alpha$-limit dex- trins were determined after quantifying the amount of cross contamination during methanol precipitation (Table 1) [7]. The methanol precipitates thus obtained (further referred to as $\alpha$-dextrin fractions) of P10-P30 and A10-A30, mainly containing $\alpha$-limit dextrins $(84-99 \%)$ [7], were extensively digested with $\beta$-amylase from Bacillus cereus, yielding $\alpha, \beta$-limit dextrins and small oligomers $[9,10]$. For each sample, the DP decreased during $\beta$-amylolysis, as could be demonstrated by ${ }^{1} \mathrm{H}$ NMR spectroscopy $[11,12]$. The $\alpha, \beta$-limit dextrins obtained from P10-P30 and A16-A30 were separated from liberated maltose by using Bio-Gel P-2 chromatography. Small $(1 \rightarrow$ 4)-linked oligomers with or without single $(1 \rightarrow 6)$ branching, originating from cross contamination during the methanol precipitation [7] and with DP up to 4, as determined by MALDI-TOF mass spectrometry, co-eluted with the maltose fraction. Determination of the substitution level by using monosaccharide analysis shows that the MS values of the $\alpha, \beta$-limit dextrins are higher than those of the corresponding $\alpha$-limit dextrins (Table 1). This can be rationalised from the mode of action of beta-amylase, because the binding of the maltosyl groups that are subsequently cleaved will be sterically hindered by the presence of methyl substituents. Not only branching points stop the digestion, but also substituted glucose residues. Since predominantly non-substituted maltose is released

Table 1

MS values of $\alpha$-limit dextrins and $\alpha, \beta$-limit dextrins from P10-P30 and A10-A30

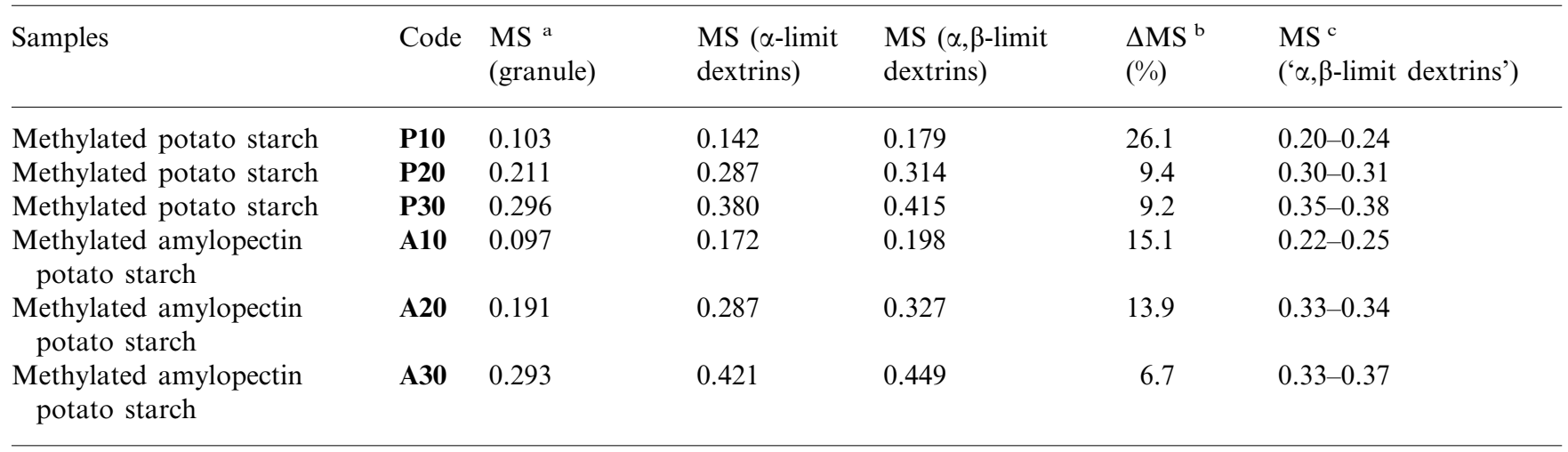

\footnotetext{
${ }^{\text {a }}$ Molar substitution (MS) is defined as mole of substituents/mole of glucose residues. MS varies from 0 (native starch) to 3 (permethylated linear starch). All MS values are determined by using GLC in triplo $(s<0.01)$.

${ }^{\mathrm{b}} \Delta \mathrm{MS}=[\mathrm{MS}(\alpha, \beta$-limit dextrins $)-\mathrm{MS}(\alpha$-limit dextrins $) / \mathrm{MS}(\alpha$-limit dextrins $)] \times 100 \%$.

${ }^{\mathrm{c}}$ Calculated MS of virtual $\alpha, \beta$-limit dextrins using Eq. (1), with $0<\mathrm{MS}_{\text {terminal }}<0.15$.
} 
from the $\alpha$-limit dextrins, the $\alpha, \beta$-limit dextrins will have higher MS values. As can be seen from Table 1, the relative increases in MS values $(\Delta \mathrm{MS})$ are larger for the lower substituted $\alpha$-limit dextrins. This observation is in agreement with the steric hindrance of betaamylase already mentioned, which is expected to increase with the MS. The P-2 maltose fraction contained small amounts of methylated glucans, probably originating from the earlier mentioned cross contamination. However, from these data it cannot be excluded that beta-amylase also liberates maltose groups of low methylation level. In conclusion, $\beta$-amylolysis of $\alpha$-limit dextrins from $\mathbf{P 1 0}-\mathbf{P 3 0}$ and $\mathbf{A 1 0}-\mathbf{A 3 0}$ results in a relative enrichment of partially methylated glucose residues in the generated $\alpha, \beta$-limit dextrins as compared with the $\alpha$-limit dextrins.

FAB mass spectrometric determination of average substitution levels of constituting residues in per(deuterio)methylated $\alpha, \beta$-limit dextrins. - The $\alpha$-dextrin fractions (mainly containing $\alpha$-limit dextrins) and the $\alpha, \beta$-limit dextrins obtained from P10-P30 and A10A30 were perdeuteriomethylated with $\mathrm{CD}_{3} \mathrm{I}$ [13], then methanolysed with methanolic $\mathrm{HCl}$ $[14,15]$. This derivatisation procedure yielded 12 mixtures all containing the three chemically different methyl glucosides (Scheme 1), namely per(deuterio)methylated methyl glucosides $\left(\mathbf{C}^{\prime}\right)$, (deuterio)methylated methyl glucosides having HO-4 free $\left(\mathbf{A}^{\prime}\right.$ and $\left.\mathbf{D}^{\prime}\right)$, and (deuterio)methylated methyl glucosides having HO-4 and HO-6 free $\left(\mathbf{B}^{\prime}\right)$.

Each mixture of three chemically different methyl glucosides (Scheme 1) was analysed by FABMS. This resulted in three sets of sodiumcationised pseudomolecular ions in the FAB spectrum. The first set had the main peak at $m / z 251\left(\mathbf{B}^{\prime}\right.$, with $\left.\mathrm{X}=\mathrm{CD}_{3}\right)$, the second at $m / z$ $268\left(\mathbf{A}^{\prime} / \mathbf{D}^{\prime}\right.$ with $\left.\mathrm{X}=\mathrm{CD}_{3}\right)$, and the third at $m / z 285\left(\mathbf{C}^{\prime}\right.$, with $\left.\mathrm{X}=\mathrm{CD}_{3}\right)$. Each set contains three pseudomolecular ions having zero, one, or two $\mathrm{CH}_{3}$ groups. Within each set, all three compounds show the same ionisation efficiency because they are chemically identical. Therefore, their FAB intensities represent the amount of each compound present in one set. Note that the intensities of the pseudomolecular ions of the three different sets of methyl glucosides $\left(\mathbf{B}^{\prime}, \mathbf{A}^{\prime} / \mathbf{D}^{\prime}\right.$, and $\left.\mathbf{C}^{\prime}\right)$ cannot be compared with each other, because of their chemical inequivalency. FAB spectra of mixtures derived from A10-A30 are shown in Fig. 1.

The sodium-cationised pseudomolecular ion at $m / z 251$ and its satellite ions at $m / z 248$ and 245 (trace amounts) originate from residues linked at O-1, O-4, and O-6 ( $\mathbf{B}^{\prime}$ in Scheme 1, with $\mathrm{X}=\mathrm{H}$ or $\mathrm{CH}_{3}$ ). Their peak intensities correspond to the amounts of non-, mono-, and disubstituted residues, respectively. From these data the average substitution level of glucose residues at branching points $\left(\mathrm{MS}_{\text {branch }}\right)$ can be calculated. The sodium-cationised pseudomolecular ion at $\mathrm{m} / z 268$ and its satellite ions at $\mathrm{m} / \mathrm{z} 265$ and 262 originate from residues linked at $\mathrm{O}-1$ and $\mathrm{O}-4$, or the reducing end ( $\mathbf{A}^{\prime}$ and $\mathbf{D}^{\prime}$ in Scheme 1, respectively, with $\mathrm{X}=\mathrm{H}$ or $\mathrm{CH}_{3}$ ). Using the ratios of the peak intensities, the average substitution level of glucose residues in linear $(1 \rightarrow 4)$-linked chains $\left(\mathrm{MS}_{\text {chain }}\right)$ can be determined. The results are summarised in Table 2.

In branched glucose residues HO-6 is not available for substitution. Therefore, $\mathrm{MS}_{\text {branch }}$ is corrected (resulting in $\mathrm{MS}_{\text {branch,cor }}$ ) by assuming that HO-6 of branched glucose residues is methylated in similar amounts as HO-6 of linearly linked glucose residues (taken from monosaccharide analysis of $\alpha, \beta$ limit dextrins). Interestingly, the corrected substitution levels of branched glucose residues $\left(\mathrm{MS}_{\text {branch,cor }}\right)$ differ only slightly from those of linearly linked glucose residues $\left(\mathrm{MS}_{\text {chain }}\right.$ ) (see Table 2). Therefore, no significant preference for substitution at either branched or linearly linked glucose residues can be concluded. In an earlier report we have shown that methyl substituents are distributed almost randomly in branched regions of methylated starches ( $\alpha$-limit dextrins) [7]. The results shown here are in good agreement with a random distribution of methyl substituents over branched regions during methylation.

The sodium-cationised pseudomolecular ions at $\mathrm{m} / \mathrm{z} 285$ and the satellite ions at $\mathrm{m} / \mathrm{z}$ 282 and 279 (trace amounts) originate from residues linked at O-1 only $\left(\mathbf{C}^{\prime}\right.$ in Scheme 1 , with $\mathrm{X}=\mathrm{H}$ or $\mathrm{CH}_{3}$ ). Since the amounts of mono- and disubstituted residues are too low for quantification, in all $\alpha, \beta$-limit dextrins the 


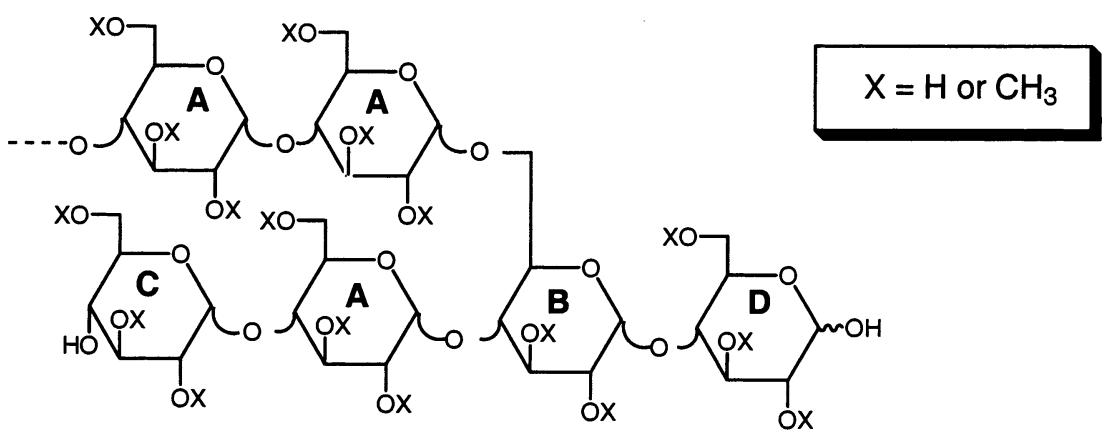

1. Perdeuteriomethylation 2. Methanolysis

$$
\mathrm{X}=\mathrm{CD}_{3} \text { or } \mathrm{CH}_{3}
$$

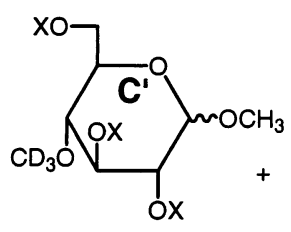

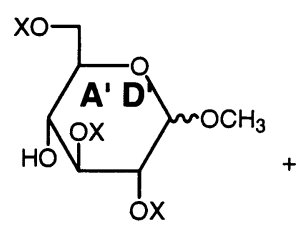

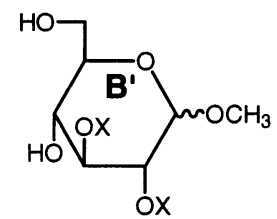

\section{Trimethylsilylation}

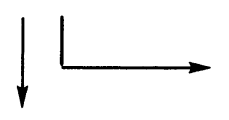

FAB mass spectrometry ( $\mathrm{MS}_{\text {branch, }} \mathrm{MS}_{\text {chain }}, \mathrm{MS}_{\text {terminal }}$ )
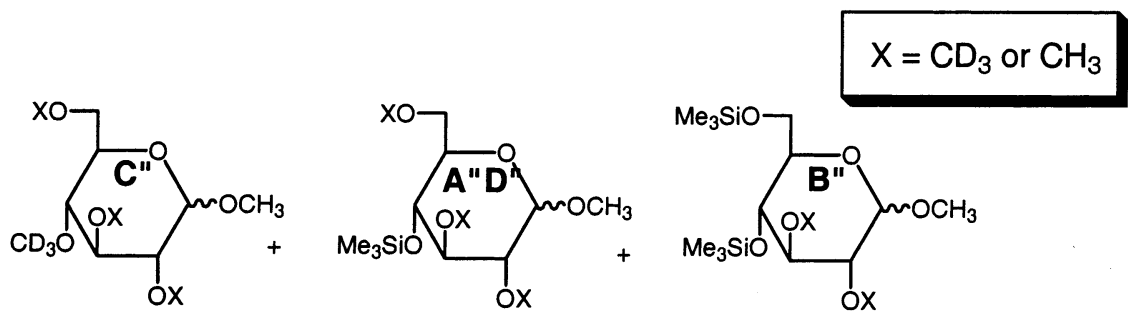

\section{GLC monosaccharide analysis} (degree of branching)

Scheme 1. Methodology for the analysis of methylation at branching points in $\alpha$-dextrin fractions and in $\alpha, \beta$-limit dextrins obtained from P10-P30 and A10-A30, and for the determination of the degree of branching (DB).

percentage of non-substituted glucose residues at the non-reducing end must be higher than $90 \%$. Therefore, the average substitution level of terminal glucose residues is lower than 0.15 $\left(\mathrm{MS}_{\text {terminal }}<0.15\right)$. This implies that alphaand beta-amylase both have a diminished ability for hydrolysis of the glycosidic linkages of saccharides in which the terminal non-reducing glucosyl group is methylated.

Determination of degree of branching. - The degree of branching (DB) of hydrolysates of methylated starches cannot be determined by 1D ${ }^{1} \mathrm{H}$ NMR spectroscopy because of overlap of (partially) methylated $\rightarrow 4)$-Glc-( $\rightarrow 6$ )residues with non-substituted $\rightarrow 4)$-Glc- $(1 \rightarrow$ residues, as is evident from Fig. 2. However, the DB may be determined by using GLC. For this purpose, each mixture of methyl glucosides obtained after perdeuteriomethylation and methanolysis of $\alpha, \beta$-limit dextrins from P10-P30 and A10-A30 was trimethylsilylated and quantitatively analysed by GLC, using empirically determined molar response factors $[16,17]$ (Fig. 3). In this way, the ratio for the residues $\mathbf{B}^{\prime \prime}, \mathbf{C}^{\prime \prime}$, and $\mathbf{A}^{\prime \prime}+\mathbf{D}^{\prime \prime}$ (Scheme 1, with $\mathrm{X}=\mathrm{H}$ or $\mathrm{CH}_{3}$ ) was determined. From this the 

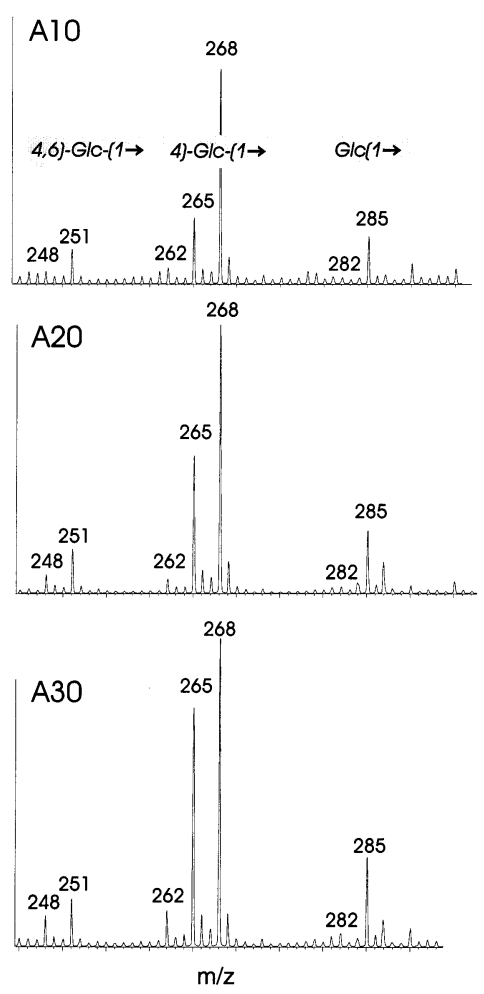

Fig. 1. FAB spectra of sodium-cationised methyl glucosides obtained from A10, A20, and A30 via perdeuteriomethylation and methanolysis. The original linkage of the methyl glucosides is indicated for A10, the corresponding structures are given in Scheme 1.

DB could be derived (multiplied by 100\% then gives the percentage of branched glucose residues present in the original polymer). The same was done for the $\alpha$-dextrin fractions from P10-P30 and $\mathbf{A 1 0}-\mathbf{A 3 0}$. The average $\mathrm{DB}$ values are given in Table 3 .

From Table 3 it is clear that the DB values

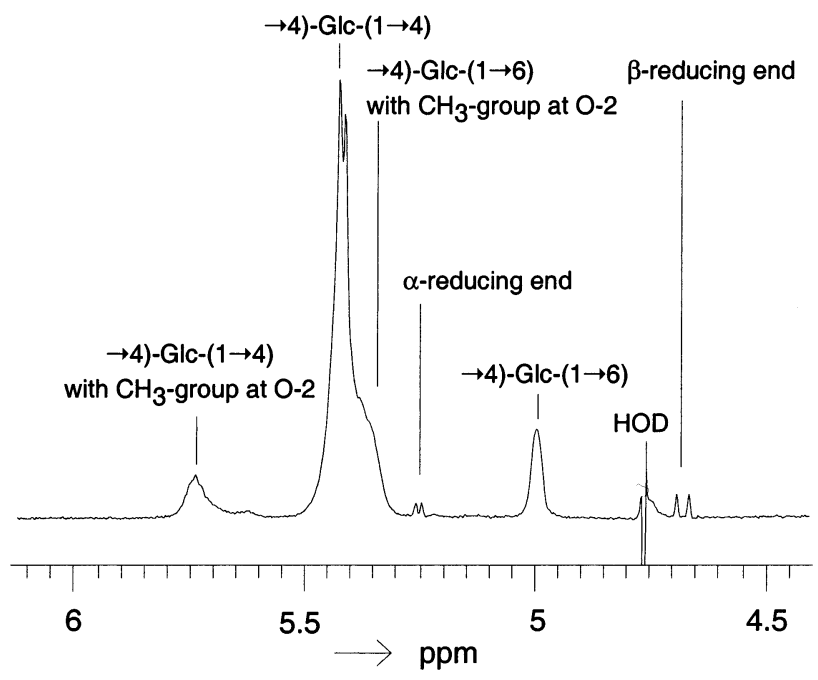

Fig. 2. ${ }^{1} \mathrm{H}$ NMR spectrum of the methanol precipitate of A20 (only signals from anomeric protons are shown).

of all $\alpha$-dextrin fractions increase after $\beta$-amylolysis. However, this increase shows no correlation with the MS. Using $\mathrm{MS}_{\text {branch }}$ and $\mathrm{MS}_{\text {chain }}$ from Table 2, and DB values from Table 3, the MS values of ' $\alpha, \beta$-limit dextrins' (reconstructed virtual $\alpha, \beta$-limit dextrins) were calculated according to Eq. (1). MS values thus obtained are summarised in Table 1.

$$
\begin{aligned}
& \text { MS (' } \alpha, \beta \text {-limit dextrins') } \\
& =\mathrm{DB} \times \mathrm{MS}_{\text {branch }}+\mathrm{DB} \times \mathrm{MS}_{\text {terminal }} \\
& \quad+[100-(2 \times \mathrm{DB})] \times \mathrm{MS}_{\text {chain }}
\end{aligned}
$$

The substitution level of terminal glucose residues $\left(\mathrm{MS}_{\text {terminal }}\right)$ is estimated to be between 0 and 0.15 (see above). As may be seen in

\begin{tabular}{|c|c|c|c|c|c|}
\hline Sample & $\begin{array}{l}\mathrm{MS}_{\text {branch values }} \\
\text { (residues linked at O-1, } \\
\mathrm{O}-4 \text {, and O-6) }\end{array}$ & $\begin{array}{l}\text { MS contribution of } 6- \\
\text { O-substituted residues }\end{array}$ & $\begin{array}{l}\mathrm{MS}_{\text {branch,cor values }} \\
\text { (residues linked at O-1, } \\
\text { O-4, and O-6) }\end{array}$ & $\begin{array}{l}\text { MS }_{\text {chain values (residues }} \\
\text { linked at O-1 and O-4) }\end{array}$ & $\Delta \mathrm{MS}^{\mathrm{d}}(\%)$ \\
\hline P10 & 0.239 & 0.022 & 0.261 & 0.287 & 10.0 \\
\hline P20 & 0.297 & 0.037 & 0.334 & 0.318 & -4.8 \\
\hline P30 & 0.373 & 0.051 & 0.424 & 0.450 & 6.1 \\
\hline A30 & 0.397 & 0.055 & 0.452 & 0.471 & 4.2 \\
\hline
\end{tabular}

Table 2

Substitution levels of residues originally linked at O-1, O-4, and O-6, and of residues originally linked at O-1 and O-4

a A third decimal is included for clarity. However, the accuracy of the measurements justifies two decimals only.

b Positional molar substitution of 6-position (from monosaccharide analysis, counting one substituent of 6-O-methyl-, 2,6-O-dimethyl-, 3,6- $O$-dimethyl-, and 2,3,6- $O$-trimethyl methyl glucoside each).

${ }^{\mathrm{c}}$ Calculated by adding the MS contribution of 6-O-substituted residues to $\mathrm{MS}_{\text {branch. }}$.

${ }^{\mathrm{d}} \Delta \mathrm{MS}_{\text {chain }}=\left[\mathrm{MS}_{\text {chain }}-\mathrm{MS}_{\text {branch,cor }} / \mathrm{MS}_{\text {branch,cor }}\right] \times 100 \%$. 


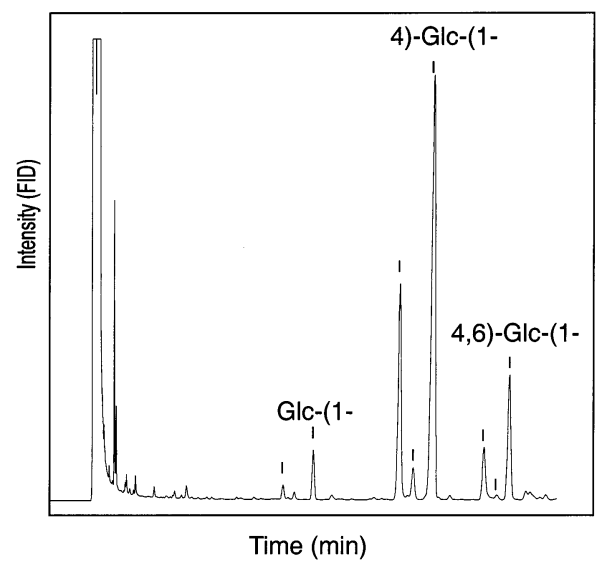

Fig. 3. Gas chromatogram of a mixture of trimethylsilylated methyl glucosides (from $\alpha, \beta$-limit dextrins of A10). The labelled peaks are of interest. The first two peaks correspond to per(deuterio)methylated methyl glucosides [originating from residues linked at $\mathrm{O}-1$ only $\left(\mathbf{C}^{\prime \prime}, \alpha / \beta\right.$-pyranose $\left.)\right]$, the next three with monosilylated (deuterio)methylated methyl glucosides [originating from residues linked at $\mathrm{O}-1$ and O-4 (A",$\alpha / \beta$ pyranose/furanose)] and the last three with disilylated (deuterio)methylated methyl glucosides [originating from residues linked at O-1, O-4, and O-6 (B", $\alpha / \beta$-pyranose/furanose)].

Table 1, the measured MS value of an $\alpha, \beta-$ limit dextrin differs significantly from the one of a reconstructed virtual $\alpha, \beta$-limit dextrin. This is mainly due to the inaccurate value of $\mathrm{MS}_{\text {terminal }}$. To obtain a more specific value of $\mathrm{MS}_{\text {terminal }}$, detailed information is needed on which partially methylated maltose fragments are tolerated by beta-amylase.

\section{Materials and methods}

Preparation of $\alpha, \beta$-limit dextrins from methylated starches. - Potato-starch granules and amylopectin potato-starch granules were methylated in an alkaline aqueous suspension by using $\mathrm{Me}_{2} \mathrm{SO}_{4}$ (see Table 1). The methylated starches obtained, P10-P30 and A10A30 were gelatinised and extensively digested with alpha-amylase from Bacillus subtilis [9] (BAN 240L from Novo). Oligomers with $\mathrm{DP}>8$ precipitated by adding $\mathrm{MeOH}$ (5 vol equiv) [7]. The $\mathrm{MeOH}$ precipitates contained mainly $\alpha$-limit dextrins and were extensively digested with beta-amylase from Bacillus cereus (Amano Pharmaceutical, Japan) in a shaking waterbath at $55^{\circ} \mathrm{C}$ and $\mathrm{pH} 5.5$, using $0.5 \mathrm{mass}^{\%} \%$ of enzyme. $\alpha, \beta$-Limit dextrins were isolated after separation from smaller oligomers $(\mathrm{DP}<5)$ by using Bio-Gel P-2 column chromatography.

Analytical procedures.-Monosaccharide analysis was carried out by subjecting partially methylated oligomer or glucan samples to methanolysis (methanolic $1 \mathrm{M} \mathrm{HCl}, 18 \mathrm{~h}$, $85^{\circ} \mathrm{C}$ ). The resulting mixtures of methyl glucoside derivatives were trimethylsilylated (1:1:5 hexamethyldisilazane-chlorotrimethylsilane-pyridine), identified by GLC-mass spectrometry, and quantified by GLC using empirical molar-response factors [7]. GLC analyses were performed on a WCOT CP-SIL 5CB fused-silica capillary column $(25 \mathrm{~m} \times$ $0.32 \mathrm{~mm}$ ) by using a temperature program of $110-230^{\circ} \mathrm{C}$ at $4{ }^{\circ} \mathrm{C} / \mathrm{min}$ and maintaining at $230{ }^{\circ} \mathrm{C}$ for $5 \mathrm{~min}$. GLC-mass spectrometry of $(\mathrm{O}$-methylated) glucose derivatives, measured as trimethylsilylated methyl glucosides, was carried out on an MD800/8060 system (Fisons instruments; electron energy, $70 \mathrm{eV}$ ), equipped with a DB-1 fused-silica capillary column (30

Table 3

Degrees of branching of $\alpha$-dextrin fractions and $\alpha, \beta$-limit dextrins from P10-P30 and A10-A30

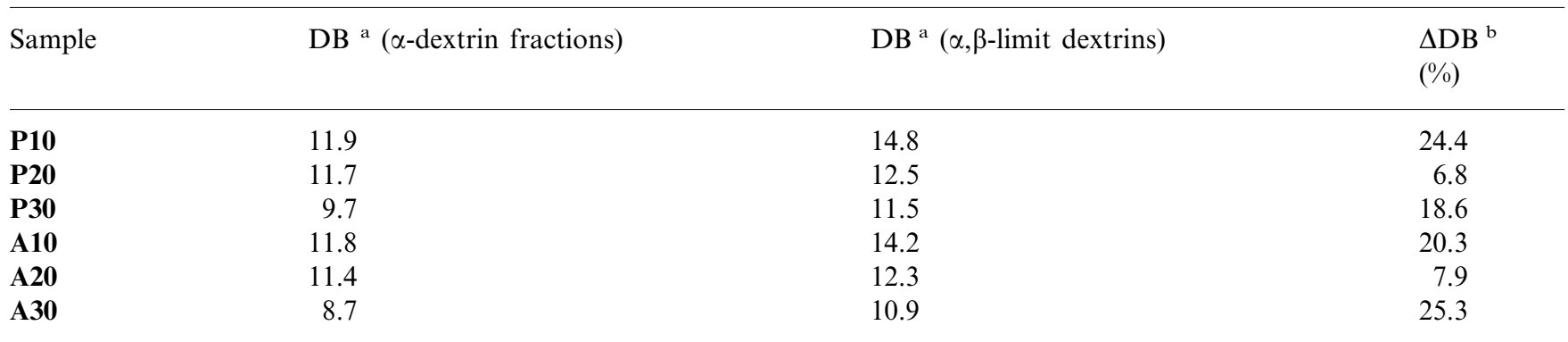

\footnotetext{
a The degree of branching (DB) is defined as the percentage of glucose residues that are branched (calculated by dividing the amount of residues linked at O-1, O-4 and O-6 by the total amount of methyl glucosides in dextrin multiplied by $100 \%$ ).

${ }^{\mathrm{b}} \Delta \mathrm{DB}=[\mathrm{DB}(\alpha, \beta$-limit dextrins $)-\mathrm{DB}(\alpha$-dextrin fractions $) / \mathrm{DB}(\alpha$-dextrin fractions $)] \times 100 \%$.
} 
$\mathrm{m} \times 0.32 \mathrm{~mm}, \mathrm{~J} \& \mathrm{~W}$ Scientific), using a temperature program of $110-230^{\circ} \mathrm{C}$ at $4{ }^{\circ} \mathrm{C} / \mathrm{min}$ and maintaining at $230^{\circ} \mathrm{C}$ for $5 \mathrm{~min}$.

Partially methylated oligomers ( $\alpha$-limit dextrins obtained after $\alpha$-amylolysis of P10, P20, P30, A10, A20, and A30 and $\alpha, \beta$-limit dextrins obtained after $\beta$-amylolysis of $\alpha$-dextrin fractions) were permethylated with $\mathrm{CD}_{3} \mathrm{I}$, as described previously $\left(\mathrm{Me}_{2} \mathrm{SO}-\mathrm{NaOH}\right)$ [13]. After methanolysis (methanolic $1 \mathrm{M} \mathrm{HCl}, 18 \mathrm{~h}$, $85^{\circ} \mathrm{C}$ ) the methyl glucosides were analysed as such by FAB mass spectrometry; for gas-chromatographic purposes (determination of DB) the methyl glucosides were trimethylsilylated as already described before injection. FAB mass spectrometry was performed on a Jeol JMS SX/SX 102A four-sector mass spectrometer, operated at $10 \mathrm{kV}$ accelerating voltage, equipped with a Jeol MS-FAB 10 D FAB gun operated at a $10 \mathrm{~mA}$ emission current, producing a beam of $6 \mathrm{keV}$ xenon atoms. The per(deuterio)methylated oligosaccharide samples were measured over a mass range of $\mathrm{m} / \mathrm{z}$ $10-1200$ in a matrix of $m$-nitrobenzyl alcohol saturated with NaI, using the standard resolution of 1500. Prior to NMR analysis, samples were exchanged once in $\mathrm{D}_{2} \mathrm{O}(99.9$ atom $\% \mathrm{D}$, Isotec), then lyophilised and dissolved in 99.96 atom $\% \mathrm{D}_{2} \mathrm{O}$ (Isotec). 1D ${ }^{1} \mathrm{H}$ NMR spectra were recorded on a Bruker AC-300 spectrometer (Department of Organic Chemistry, Utrecht University), equipped with a $5 \mathrm{~mm}$ broad-band probe, at a probe temperature of $27^{\circ} \mathrm{C}$. Chemical shifts are expressed in ppm downfield from the signal for external $\mathrm{Me}_{4} \mathrm{Si}$, but were actually measured by reference to external acetone $(\delta$ 2.225). The data were collected in $16 \mathrm{~K}$ complex data sets and zerofilled to $32 \mathrm{~K}$. After Fourier transformation, using a Gaussian multiplication, the spectra were integrated with Bruker software.

\section{Acknowledgements}

This study was supported by the PBTS Research Program with financial aid from the Ministry of Economic Affairs and the Integral Structure Plan for the Northern Netherlands from the Dutch Development Company. The authors thank Ms A. van der Kerk-van Hoof and $\mathrm{Mr} \mathrm{C}$. Versluis for their contributions to the FAB mass spectrometric results.

\section{References}

[1] Y. Takeda, S. Tomooka, S. Hizukuri, Carbohydr. Res., 246 (1993) 267-272.

[2] A. Imberty, S. Pérez, Biopolymers, 27 (1988) $1205-$ 1221.

[3] A. Imberty, H. Chanzy, S. Pérez, A. Buléon, V. Tran, Macromolecules, 20 (1987) 2634-2636.

[4] S. Hizukuri, Carbohydr. Res., 147 (1986) 342-347.

[5] D. Sievert, J. Holm, Starch/Stärke, 45 (1993) 136-139.

[6] O.B. Wurzburg (Ed.), Modified Starches: Properties and Uses, CRC Press, Boca Raton, FL, 1986.

[7] Y.E.M. van der Burgt, J. Bergsma, I.P. Bleeker, P.J.H.C. Mijland, A. van der Kerk-van Hoof, J.P. Kamerling, J.F.G. Vliegenthart, Carbohydr. Res., 312 (1998) 201-208.

[8] Y.E.M. van der Burgt, J. Bergsma, I.P. Bleeker, P.J.H.C. Mijland, A. van der Kerk-van Hoof, J.P. Kamerling, J.F.G. Vliegenthart, Carbohydr. Res., 320 (1999) $100-107$.

[9] J.F. Robyt, Starch, second ed., Academic Press, New York, 1984, pp. 87-123.

[10] E. Bertoft, Carbohydr. Res., 189 (1989) 195-207.

[11] M.J. Gidley, Carbohydr. Res., 139 (1985) 85-93.

[12] J.D. Blake, M.L. Clarke, J. Littlemore, Carbohydr. Res., 138 (1985) 161-167.

[13] I. Ciucanu, F. Kerek, Carbohydr. Res., 131 (1984) 209-217.

[14] J.P. Kamerling, J.F.G. Vliegenthart, in A.M. Lawson (Ed.), Clinical Biochemistry - Principles, Methods, Applications, Vol. 1, Walter de Gruyter, Berlin, 1989, pp. 176-263.

[15] M.F. Chaplin, Anal. Biochem., 123 (1982) 336-341.

[16] J.T. Scanlon, D.E. Willis, J. Chromatogr. Sci., 23 (1985) 333-339.

[17] A.D. Jorgensen, K.C. Picel, V.C. Stamoudis, Anal. Chem., 62 (1990) 683-689. 